\title{
A Prospective Controlled Study of Magnetic Resonance Imaging of the Brain in Gay Men and Parenteral Drug Users With Human Immunodeficiency Virus Infection
}

\author{
George Dooneief, MD; Jacqueline Bello, MD; George Todak, MSW; In K. Mun, PhD; Karen Marder, MD; \\ Renée Malouf, MD; Jack Gorman, MD; Sadek Hilal, MD, PhD; Yaakov Stern, PhD; Richard Mayeux, MD
}

\begin{abstract}
- To detect the earliest structural changes in the brain in human immunodeficiency virus (HIV) infection, 118 gay men and 115 parenteral drug users enrolled in a study of the natural history of HIV infection underwent magnetic resonance imaging evaluations. Routine $\mathrm{T}_{2}$-weighted and heavily $\mathrm{T}_{2}$-weighted scans for quantification of brain water were obtained, blinded to HIV serostatus. Atrophy and foci of increased signal did not correlate with any medical, immunologic, neurologic, or neuropsychologic parameters in the group as a whole, or in the gay men or parenteral drug user subgroups. Three subjects had progressive multifocal leukoencephalopathy and one had central nervous system lymphoma. In a subgroup in whom intracranial water percent was calculated, correlations were found with CD4 counts and CD4/CD8 ratios. We conclude that standard magnetic resonance imaging of the brain does not differentiate asymptomatic and mildly symptomatic HIV-positive individuals from HIV-negative individuals, regardless of risk group. However, intracranial water percent may distinguish HIV-positive from HIVnegative individuals because it correlates with raw $C D 4$ counts and $C D 4 / C D 8$ ratios.
\end{abstract}

(Arch Neurol. 1992;49:38-43)

M agnetic resonance imaging (MRI) of the brain in patients with acquired immunodeficiency syndrome (AIDS) with neurologic signs or symptoms has demonstrated atrophy, white matter changes, and mass lesions..$^{1.7}$ Clinical progression and abnormalities on subsequent scans have been predicted by brain atrophy noted on computed tomographic scans of patients with AIDS. ${ }^{1}$ We developed a quantitative measure of atrophy in MRI in an attempt to detect the earliest structural change in the human immunodeficiency virus (HIV)-infected brain and its relationship to medical, neurologic, and neuropsychologic manifestations of HIV disease.

Accepted for publication June 4, 1991

From the HIV Center for Clinical and Behavioral Studies, New York State Psychiatric Institute (Drs Dooneief, Marder, Malouf, Gorman, Stern, and Mayeux and Mr Todak), and the Departments of Neurology (Drs Dooneief, Marder, Malouf, Stern, and Mayeux), Radiology (Drs Bello, Mun, and Hilal), and Psychiatry (Drs Gorman, Stern, and Mayeux), Columbia University College of Physicians and Surgeons, New York, NY.

Reprint requests to Neurological Institute, 710 W 168th St, New York, NY 10032 (Dr Mayeux)

\section{SUBJECTS AND METHODS Subjects}

Subjects being followed up in a prospective study of the natural history of HIV infection that began in March 1988 (the follow-up study ${ }^{8}$ ) were recruited to participate in an MRI study that began in September 1989. The original study group consisted of volunteers from gay men's organizations, an infectious disease clinic, and a methadone maintenance clinic and were solicited through newspaper advertisements and by word of mouth.

Inclusion criteria for the larger follow-up study from which our subjects were recruited were as follows: (1) age between 18 and 60 years, (2) gay or bisexual man without selfadministration of parenteral drugs more than 10 times since 1982 (gay men cohort) or history of parenteral drug use at least 10 times since 1982 (parenteral drug user [PDU] cohort), (3) prior knowledge of HIV status, and (4) proficiency in English.

Exclusion criteria were as follows: (1) the Centers for Disease Control National Surveillance Criteria for AIDS at the time of enrollment, with the exception of AIDS dementia and esophageal candidiasis; (2) presence of an encephalopathy unrelated to HIV infection (eg, posttraumatic dementia), and (3) presence of a chronic neurologic disorder antedating HIV infection (eg, epilepsy requiring continuing therapy).

Three hundred eighty-two subjects were in the follow-up study at the beginning of the MRI study. Two hundred thirty-seven were scanned between September 1989 and $\mathrm{Au}-$ gust 1990 . Of the remaining 145 subjects, 56 refused the test, 32 were unable to undergo the procedure because of claustrophobia, 10 were incarcerated, nine died, eight dropped out of the study, seven were excluded because of metal implants, four could not be scanned because of machine breakdown or maintenance, four had inadequate or incomplete scans, and 15 subjects could not be located.

The biannual assessments in the follow-up study have been described in detail elsewhere ${ }^{8,9}$ and are summarized below.

\section{Medical Evaluation}

Medical evaluation included complete blood cell count, CD4 and CD8 counts, and a physical examination performed by a physician "blind" to the subject's HIV status. Review of these data allowed the classification of each subject as HIV-negative, HIV-positive asymptomatic, and HIV-positive with mild symptoms (primarily enlarged lymph nodes), with AIDS-related complex, or with AIDS.

\section{Neurologic Evaluation}

All neurologic evaluations were performed by neurologists blinded to HIV serostatus. Constellations of signs associated with the central and peripheral nervous system were assessed to rate impairment in nine categories of neurologic function: mental (as assessed by a brief 19-item mental status test), visual (scotoma or diminished acuity), brain stem (nystagmus, extraocular muscle weakness, or dysarthria), pyramidal (deficient rapid alternating movements, paraparesis, or hemiparesis), extrapyramidal (rigidity, bradykinesia, or tremor), cerebellar (ataxia), sensory (vibratory loss or stocking/glove neuropathy), bowel/bladder (urgency or incontinence), and peripheral nerve (weakness, pain, or sensory loss in an asymmetric distribution, excluding stocking/glove neuropathy).

A summary score was calculated based on a modified version of the Kurtzke Disability Status Scale for Multiple Sclerosis ${ }^{10}$ to reflect the overall degree of neurologic disability.

\section{Neuropsychologic Evaluation}

Neuropsychologic testing was also performed blinded to serostatus. All subjects underwent tests of general intelligence (a modified version of the Mini-Mental State examination ${ }^{11}$ ), abstract reasoning (the Wechsler Adult Intelligence Scale-Revised [WAIS-R] similarities subtest ${ }^{12}$ ), verbal and nonverbal memory (the Selective Reminding test $^{13}$ and the Wechsler Memory Scale-Revised [WMS-R] visual reproduction subtest $^{14}$ ), language (the Boston Naming test, ${ }^{15}$ the Controlled Oral Word Association test, ${ }^{16}$ and the Sentence Repetition subtest of the Boston Diagnostic Aphasia Examination ${ }^{17}$ ), executive function (the Odd-Man-Out test ${ }^{18}$ and the Trail Making test ${ }^{19}$ ), visuospatial ability (the WAIS-R Block Design subtest ${ }^{12}$ ), and attention (two cancellation tasks, ${ }^{20}$ the WAIS-R Digit Symbol subtest, ${ }^{12}$ and the WAIS-R Digit Span subtest ${ }^{12}$ ). In addition, the gay men underwent the conceptual levels and analogies test, ${ }^{21}$ the Benton Visual Retention test, ${ }^{22}$ the Stroop Color-Word test, ${ }^{23}$ the Benton Line Orientation test, ${ }^{24}$ a 24 -item version of the Raven's Progressive Matrices, ${ }^{2,5}$ and a 20 -trial choice reaction time task.

Performance on each test was compared with norms for age- and education-matched populations and then rated as normal, borderline (at least $1 \mathrm{SD}$ below expected mean), or defective (at least 2 SDs below the expected mean). A global performance rating (GPR) was derived to summarize overall neuropsychologic performance with respect to these norms. On this scale, a score of 0 was given for normal performance on all tests, a score of 1 for borderline performance in one 
or more areas, a score of 2 for defective performance in one area, a score of 3 for defective performance in two or more areas exclusive of memory, and a score of 4 for defective performance in memory and two or more other areas.

A clinical impression of neuropsychologic performance $(0$, normal; 1 , borderline; or 2 , abnormal) was generated based on a consensus of opinion of two experienced neuropsychologists who reviewed the test scoles independently and who were blinded to the serostatus

\section{MRI}

Scans were performed on a 1.5-tesla system. The imaging protocol consisted of $\mathrm{T}_{2}$ weighted axial and coronal scans $(\mathrm{TR}=3500$ and $\mathrm{TE}=80)$, with a slice thickness of $5 \mathrm{~mm}$ and a $4 \mathrm{~mm}$ yap. Images were acquired on a $512 \times 512$ matrix. An additional heavily $\mathrm{T}$.,-weighted scan $(\mathrm{TR}=7100$ and $\mathrm{TE}=280)$ was obtained in the axial plane only, for quantification of brain water.

In a smail pilot study before this investigation began, there was complete concordance between two neuroradiologists (J.B. and S.H.) in their assessment of degree of atrophy, presence of high signal foci, and other lesions.

In the present study, standard $\mathrm{T}_{y}$-weighted scans were evaluated by a single neuroradiologist (J.B.) who took into account each subject's age but was blinded as to their serostatus and other clinical details. Scan quality was rated as excellent, adequate, inadequate, or incomplete, and only data from excellent or adequate scans were included in the analysis. Atrophy, small areas of high signal intensity, larger focal lesions, and other" abnormalities were recorded.

Atrophy was rated as absent, mild, moderate, or marked for each subject's age (Figs 1 through 3). Focal atrophy was scored as present or absent for each cerebral lobe, the sylvian fissures, brain stem, cerebellar hemispheres, and vermis. If atrophy was only cortical (ie, sulcal enlargement without ventricular enlargement), this was also noted. For a scan to receive a rating of moderate atrophy, both the sulcal prominence and the ventricular size had to, in the estimation of the neuroradiologist, be sufficient to suggest that this was a normal scan for a person approximately 20 years older than the subject's age. Scans with sulcal prominence and ventricular size deemed abnor'mal for a person 20 vears older than the subject were rated marked atrophy. On the other hand, the presence of focal atrophy or diffuse atrophy to any lesser degree received a designation of mild atrophy. Consequently, this last category included a wide spectrum of scans.

Small foci of high-signal intensity $(3 \mathrm{~mm}$ or greater and less than $2 \mathrm{~cm}$ ) were rated as absent, single, few (less than five and less than two confluent), multiple (five or greater or two confluent), or diffuse (many confluent or foci of $2 \mathrm{~cm}$ or greater), and their number and locations were recorded (Fig 1). Differentiating small high-signal foci from cerebrospinal fluid (CSF) spaces was problematic with the standard pulse sequence. Therefore, we required a high-signal focus to be seen in both axial and coronal planes, clearly

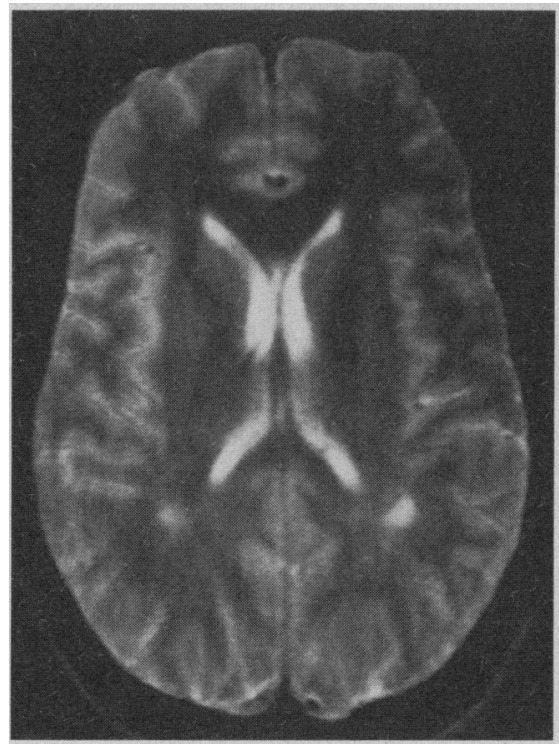

Fig 1.-Axial $\mathrm{T}_{2}$-weighted image of a 37-yearold subject without atrophy. Two periventricular foci of increased signal are noted.

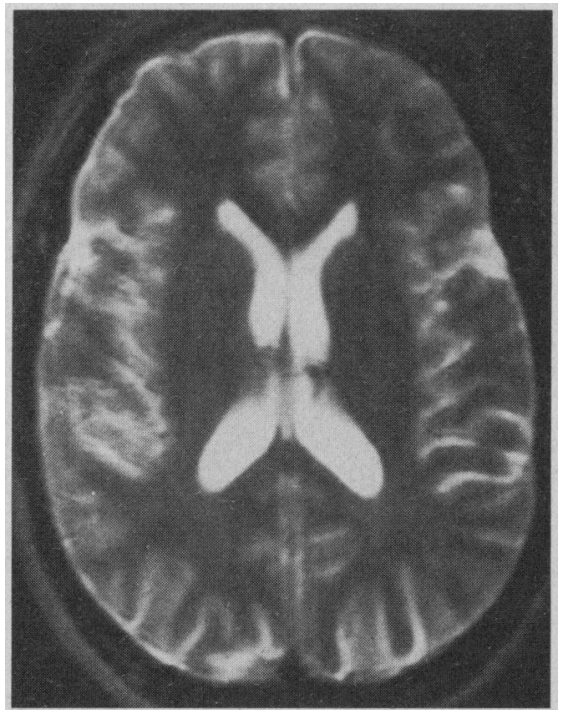

Fig 3. - Left, Axial T2-weighted image of a 39-year-old subject with mild atrophy. Right, Heavily $\mathrm{T}_{2}$ weighted image of the same scan section as in the image on the left.

separated from sulci, eisterns, and the ventricular system.

Larger focal lesions consistent with opportunistic infections or neoplasms were also noted, as were other abnormalities (eg, arteriovenous malformations, strokes, or sinusitis).

The percentage of the intracranial cavity occupied by the CSF was quantitated using the heavily $\mathrm{T}$-weighted scans (Fig 3). These images demonstrate a bright signal generat ed by protons in water molecules with a very long $\mathrm{T}_{2}$ (eg, within the CSF, globes, and inflamed sinuses), and essentially no signal is generated by the brain or other soft tissue. A cursor was used to trace the inner table of the skull in each scan section. The maximum brightness (corresponding to an area of CSF) within the traced area was scaled by computer to a value of 255 . If a given pixel contained CSF only, it was given a value of 255 and if
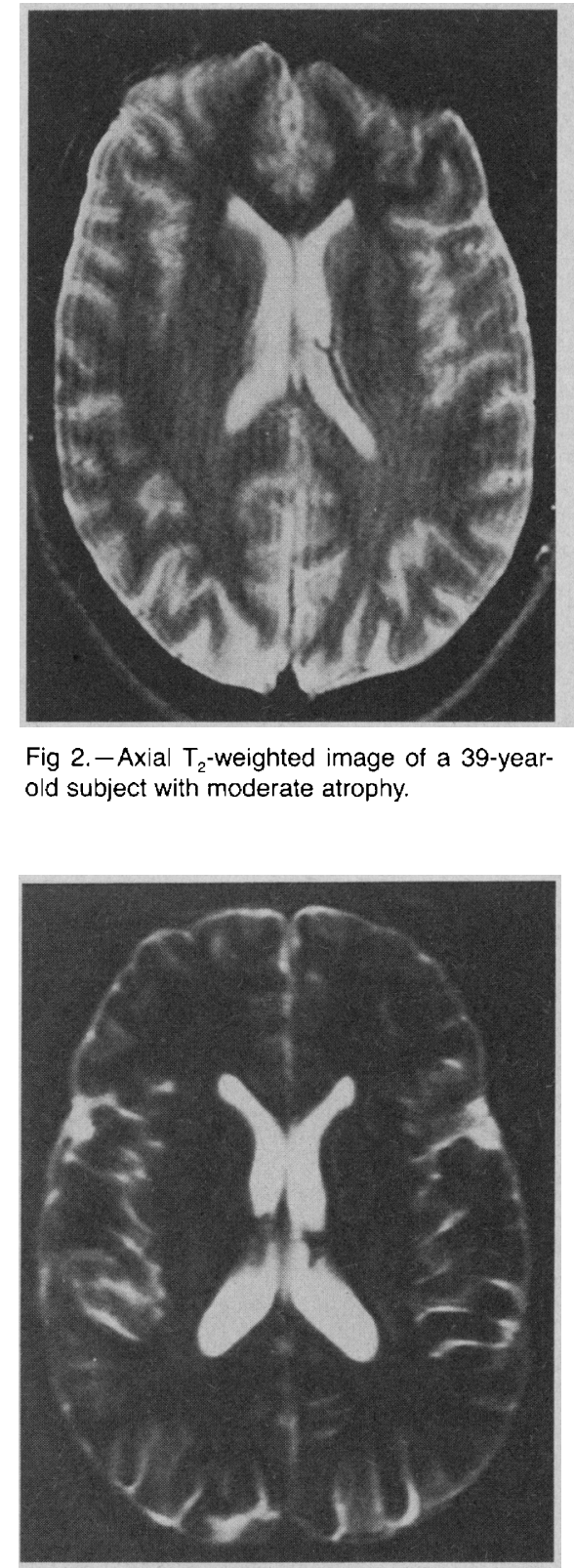

Fig 2.-Axial $T_{2}$-weighted image of a 39-yearold subject with moderate atrophy.

there was a partial volume effect, the value was scaled in proportion to the amount of brain sharing the pixel with the CSF. If the entire pixel contained only brain, the value was 0 . Software was developed to calculate the area within the outlined region of interest and also the total signal within this perimeter. The proportion of the intracranial cavity consisting of CSF was computed by adding the total signal from each scan section and dividing by the total area within the scan multiplied by 255 , ie,

(Scaled Pixel Values Within Traced Regions)/

[(Pixels Within Traced Regions $) \times 255]$

$=$ Proportion $\mathrm{CSF}$

To validate this technique, "phantom" studies using objects suspended in water demonstrated greater than $95 \%$ accuracy of 
MRI-calculated volumes compared with measured volumes; reproducibility was better than $97 \%$.

Subjects whose MRI scans demonstrated a lesion believed to warrant further investigation were contacted by the study coordinator, and the scans were discussed with one of the study neurologists.

\section{Data Analysis}

Analysis of variance and statistical methods for rates and proportions were used to compare characterisitics of the various groups. ${ }^{26,22}$ In the initial analysis, summary measures were used for the medical, neurologic, and neuropsychologic parameters to reduce the number of comparisons and strengthen the relationships found to be statistically significant. It would also decrease the likelihood of chance associations (ie, there would be a tendency toward type II rather than type I error).

Thus, we used $x^{2}$ tests for ordered/categorical data collapsed into two categories (eg, normal vs abnormal and present vs ab. sent) to look at the relationships among atrophy, white-matter signal hyperintensities (WMH), overall neurologic disability, global neuropsychologic performance, clinical neuropsychologic impression, and HIV serostatus in the group as a whole, as well as in a variety of subgroups, ie, HIV-positive, HIVnegative, gay men, PDUs, HIV-positive gay men, HIV-negative gay men, HIV-positive PDUs and HIV-negative PDUs. To assess group differences for interval data (age, education, CD4 count and CD4/CD8 ratio) in independent groups (HIV-positive/HIVnegative, gay men/PDUs, HIV-positive gay men/HIV-negative gay men, HIV-positive PDUs/HIV-negative PDUs, HIV-positive gay men/HIV-positive PDUs, HIV-negative gay men/HIV-negative PDUs, WMH present/WMH absent, and atrophy absent or mild/atrophy moderate or marked), we employed a $t$ test for independent samples and analysis of variance. Pearson correlations for interval data (age, CD4, CD4/CD8 ratio, intracranial water percent $[\% \mathrm{CSF}])$, and also partial correlations controlling for age were performed in the group as a whole, as well as in a variety of subgroups. Last, to assess group differences in \% CSF, analyses of covariance (controlling for age) were performed with respect to stage, cohort, WMH, atrophy, and HIV serostatus.

\section{RESULTS}

The subjects are described in Tables 1 and 2. There were no significant differences in age, education, GPR, clinical neuropsychologic impression, or overall neurologic disability between the HIVpositive and HIV-negative subjects. The baseline neurologic and neuropsychologic data in the gay men cohort are described elsewhere, ${ }^{9}$ and the baseline PDU data have been submitted for publication. The raw data are available on request.

The scan results are displayed in Tables 3 and 4 . Ninety-seven percent of the scans revealed at least a mild degree of atrophy ( $77 \%$ mild and $20 \%$ moder-

\begin{tabular}{|c|c|c|c|c|c|c|c|c|c|}
\hline & \multirow[b]{2}{*}{ All } & \multicolumn{4}{|c|}{ Gay Men } & \multicolumn{4}{|c|}{ PDUs } \\
\hline & & All & HIV+ & HIV- & H & All & HIV+ & HIV- & 4 \\
\hline$n$ & 233 & 118 & 75 & 38 & 5 & 115 & 54 & 52 & 9 \\
\hline Age, y & $\begin{array}{c}39.7 \\
(7.8)\end{array}$ & $\begin{array}{c}39.8 \\
(8.3)\end{array}$ & $\begin{array}{r}39.3 \\
(8.0)\end{array}$ & $\begin{array}{c}40.7 \\
(9.0)\end{array}$ & $\ldots$ & $\begin{array}{c}39.7 \\
(7.4)\end{array}$ & $\begin{array}{l}40.0 \\
(6.8)\end{array}$ & $\begin{array}{r}38.9 \\
(7.6)\end{array}$ & $\ldots$ \\
\hline $\begin{array}{c}\text { Education, } \\
y\end{array}$ & $\begin{array}{c}14.0 \\
\text { (3.3) }\end{array}$ & $\begin{array}{c}16.4 \\
(2.3)\end{array}$ & $\begin{array}{c}16.0 \\
(2.2)\end{array}$ & $\begin{array}{c}17.3 \\
(2.2)\end{array}$ & $\ldots$ & $\begin{array}{l}11.6 \\
(2.3)\end{array}$ & $\begin{array}{l}11.7 \\
(2.1)\end{array}$ & $\begin{array}{c}11.5 \\
(2.4)\end{array}$ & \\
\hline GPR & $\begin{array}{c}1.26 \\
(1.2)\end{array}$ & $\begin{array}{c}0.77 \\
(1.0)\end{array}$ & $\begin{array}{c}0.92 \\
(1.0)\end{array}$ & $\begin{array}{l}0.47 \\
(0.9)\end{array}$ & $\ldots$ & $\begin{array}{c}1.73 \\
(1.3)\end{array}$ & $\begin{array}{c}1.75 \\
(1.3)\end{array}$ & $\begin{array}{c}1.72 \\
(1.3)\end{array}$ & \\
\hline Neurimp & $\begin{array}{l}0.58 \\
(0.8)\end{array}$ & $\begin{array}{c}0.21 \\
(0.5)\end{array}$ & $\begin{array}{l}0.25 \\
(0.6)\end{array}$ & $\begin{array}{l}0.12 \\
(0.4)\end{array}$ & & $\begin{array}{c}0.94 \\
(0.9)\end{array}$ & $\begin{array}{l}0.85 \\
(0.9)\end{array}$ & $\begin{array}{c}1.02 \\
(0.9)\end{array}$ & \\
\hline Kurtzke & $\begin{array}{c}1.68 \\
(1.6)\end{array}$ & $\begin{array}{l}1.11 \\
(0.7)\end{array}$ & $\begin{array}{c}1.14 \\
(0.7)\end{array}$ & $\begin{array}{l}1.11 \\
(0.7)\end{array}$ & & $\begin{array}{l}2.25 \\
(1.9)\end{array}$ & $\begin{array}{l}2.09 \\
(0.8)\end{array}$ & $\begin{array}{l}2.44 \\
(2.7)\end{array}$ & \\
\hline $\begin{array}{l}\text { CD4, } \\
\text { No. } / \mathrm{mm}^{3}\end{array}$ & $\begin{array}{l}578.1 \\
(385)\end{array}$ & $\begin{array}{l}494.6 \\
(341)\end{array}$ & $\begin{array}{l}394.3 \\
(290)\end{array}$ & $\begin{array}{l}867.1 \\
(247)\end{array}$ & . & $\begin{array}{c}627.3 \\
(403)\end{array}$ & $\begin{array}{c}346.5 \\
(215)\end{array}$ & $\begin{array}{c}935.6 \\
(322)\end{array}$ & $\ldots$ \\
\hline $\begin{array}{l}\mathrm{CD} 4 / \\
\mathrm{CD} 8 \text { ratio }\end{array}$ & $\begin{array}{c}0.81 \\
(0.6)\end{array}$ & $\begin{array}{c}0.69 \\
(0.5)\end{array}$ & $\begin{array}{l}0.50 \\
(0.4)\end{array}$ & $\begin{array}{c}1.40 \\
(0.4)\end{array}$ & & $\begin{array}{l}0.88 \\
(0.6)\end{array}$ & $\begin{array}{l}0.41 \\
(0.3)\end{array}$ & $\begin{array}{c}1.39 \\
(0.5)\end{array}$ & \\
\hline
\end{tabular}

*PDUs indicates parenteral drug users; HIV, human immunodeficiency virus; plus and minus signs, positive and negative, respectively; star, missing data; GPR, global neuropsychologic performance rating; Neurlmp, clinical neuropsychologic impression; and Kurtzke, a measure of overall neurologic disability modified from the Kurtzke Disability Status Scale for Multiple Sclerosis. ${ }^{10}$ Numbers in parentheses are SDs.

\begin{tabular}{|c|c|c|c|c|c|c|c|c|c|c|}
\hline & \multicolumn{10}{|c|}{ Table 2.-Study Subjects Stratified by Risk Group and Clinical Stage* } \\
\hline & \multicolumn{5}{|c|}{ Gay Men, Stage } & \multicolumn{5}{|c|}{ PDUs, Stage } \\
\hline & 0 & 1 & 2 & 3 & 4 & 0 & 1 & 2 & 3 & 4 \\
\hline$n$ & 38 & 14 & 21 & 35 & 5 & 52 & 5 & 12 & 33 & 4 \\
\hline Age, $y$ & $\begin{array}{l}40.7 \\
(9.0)\end{array}$ & $\begin{array}{c}40.1 \\
(7.4)\end{array}$ & $\begin{array}{l}40.3 \\
(8.5)\end{array}$ & $\begin{array}{l}38.2 \\
(8.3)\end{array}$ & $\begin{array}{c}41.2 \\
(8.3)\end{array}$ & $\begin{array}{c}38.9 \\
(7.6)\end{array}$ & $\begin{array}{c}44.4 \\
(4.2)\end{array}$ & $\begin{array}{l}37.1 \\
(4.4)\end{array}$ & $\begin{array}{c}41.1 \\
(7.5)\end{array}$ & $\begin{array}{r}34.9 \\
(3.7)\end{array}$ \\
\hline $\begin{array}{c}\text { Education, } \\
y\end{array}$ & $\begin{array}{c}17.3 \\
(2.2)\end{array}$ & $\begin{array}{c}16.2 \\
(1.8)\end{array}$ & $\begin{array}{c}16.9 \\
(2.3)\end{array}$ & $\begin{array}{c}15.6 \\
(2.2)\end{array}$ & $\begin{array}{c}14.8 \\
(2.8)\end{array}$ & $\begin{array}{c}11.5 \\
(2.4)\end{array}$ & $\begin{array}{c}12.4 \\
(1.8)\end{array}$ & $\begin{array}{c}11.5 \\
(1.5)\end{array}$ & $\begin{array}{c}11.7 \\
(1.7)\end{array}$ & $\begin{array}{l}12.0 \\
(2.5)\end{array}$ \\
\hline GPR & $\begin{array}{l}0.47 \\
(0.9)\end{array}$ & $\begin{array}{c}1.00 \\
(1.0)\end{array}$ & $\begin{array}{l}0.67 \\
(1.0)\end{array}$ & $\begin{array}{l}0.97 \\
(1.0)\end{array}$ & $\begin{array}{l}1.40 \\
(0.9)\end{array}$ & $\begin{array}{c}1.72 \\
(1.3)\end{array}$ & $\begin{array}{l}2.00 \\
(1.4)\end{array}$ & $\begin{array}{l}2.09 \\
(1.2)\end{array}$ & $\begin{array}{c}1.67 \\
(1.2)\end{array}$ & $\begin{array}{l}1.25 \\
(1.5)\end{array}$ \\
\hline Neurlmp & $\begin{array}{l}0.12 \\
(0.4)\end{array}$ & $\begin{array}{c}0.07 \\
(0.3)\end{array}$ & $\begin{array}{l}0.19 \\
(0.5)\end{array}$ & $\begin{array}{l}0.28 \\
(0.6)\end{array}$ & $\begin{array}{l}0.80 \\
(1.1)\end{array}$ & $\begin{array}{c}1.02 \\
(0.9)\end{array}$ & $\begin{array}{l}0.40 \\
(0.9)\end{array}$ & $\begin{array}{l}1.18 \\
(0.9)\end{array}$ & $\begin{array}{c}0.79 \\
(0.9)\end{array}$ & $\begin{array}{l}1.00 \\
(1.2)\end{array}$ \\
\hline Kurtzke & $\begin{array}{l}1.11 \\
(0.7)\end{array}$ & $\begin{array}{l}0.79 \\
(0.7)\end{array}$ & $\begin{array}{l}1.29 \\
(0.6)\end{array}$ & $\begin{array}{l}1.06 \\
(0.6)\end{array}$ & $\begin{array}{c}2.00 \\
(1.2)\end{array}$ & $\begin{array}{l}2.44 \\
(2.7)\end{array}$ & $\begin{array}{l}2.00 \\
(0.7)\end{array}$ & $\begin{array}{l}1.75 \\
(0.9)\end{array}$ & $\begin{array}{l}2.21 \\
(0.8)\end{array}$ & $\begin{array}{l}1.25 \\
(0.5)\end{array}$ \\
\hline $\begin{array}{c}\mathrm{CD} 4, \mathrm{No} .1 \\
\mathrm{~mm}^{3}\end{array}$ & $\begin{array}{r}867.1 \\
(247)\end{array}$ & $\begin{array}{r}448.5 \\
(188)\end{array}$ & $\begin{array}{l}493.7 \\
(326)\end{array}$ & $\begin{array}{l}354.1 \\
(292)\end{array}$ & $\begin{array}{r}20.00 \\
(19.9)\end{array}$ & $\begin{array}{l}935.6 \\
(322)\end{array}$ & $\begin{array}{r}537.6 \\
(114)\end{array}$ & $\begin{array}{l}351.3 \\
(213)\end{array}$ & $\begin{array}{r}324.1 \\
(229)\end{array}$ & $\begin{array}{r}266.8 \\
(78)\end{array}$ \\
\hline $\begin{array}{c}\mathrm{CD} 4 / \mathrm{CD} 8 \\
\text { ratio }\end{array}$ & $\begin{array}{l}1.40 \\
(0.4)\end{array}$ & $\begin{array}{c}0.63 \\
(0.3)\end{array}$ & $\begin{array}{l}0.67 \\
(0.4)\end{array}$ & $\begin{array}{l}0.41 \\
(0.4)\end{array}$ & $\begin{array}{l}0.04 \\
(0.0)\end{array}$ & $\begin{array}{c}1.39 \\
(0.5)\end{array}$ & $\begin{array}{l}0.65 \\
(0.3)\end{array}$ & $\begin{array}{l}0.44 \\
(0.3)\end{array}$ & $\begin{array}{l}0.36 \\
(0.2)\end{array}$ & $\begin{array}{l}0.38 \\
(0.2)\end{array}$ \\
\hline
\end{tabular}

"PDUs indicates parenteral drug users; GPR, global performance rating; Neurlmp, clinical neuropsychological impression; Kurtzke, overall neurological disability. Numbers in parentheses are SDs. Stage 0 indicates human immunodeficiency virus (HIV) negative; 1, HIV positive, asymptomatic; 2, HIV positive, with mild symptoms (eg, enlarged lymph nodes); 3 , acquired immunodeficiency syndrome-related complex; and 4 , acquired immunodeficiency syndrome.

ate). This preponderance of mild atrophy, even among the HIV-negative subjects, was surprising. In part, it may stem from the subjective criteria used for assessing atrophy. As a result of the schema outlined in the "Subjects and Methods" section, cases with mild or no atrophy were grouped together and contrasted with moderate or marked atrophy. Foci of increased signal on the $\mathrm{T}_{2}$-weighted images were noted in $20 \%$ of cases. Eight subjects had other abnormalities on their scans. In four, these were consistent with AIDS-related illnesses (three cases of progressive multifocal leukoencephalopathy and one case of CNS lymphoma), and in the other four cases the abnormalities were believed to be unrelated to AIDS (two cerebral infarctions, one arteriovenous malformation, and one para-atrial cho- roid fissure cyst).

In the standard $\mathrm{T}_{2}$-weighted scans, we examined the relationships between atrophy and WMH and the medical, neurologic and neuropsychologic data first in the entire group and then in the following subgroups: HIV-positive subjects, HIV-negative subjects, gay men, PDUs, HIV-positive gay men, HIVnegative gay men, HIV-positive PDUs, and HIV-negative PDUs.

In the group as a whole, atrophy was not related to GPR, the clinical neuropsychologic impression, the overall degree of neurologic disability, CD4 count, or HIV serostatus. However, moderate atrophy was more common in the gay men than in the PDUs $\left(\chi^{2}=8.8, P=.003\right)$. There was no relationship between WMH and GPR, clinical neuropsychologic impression, 
Table 3.-Results of Routine $T_{2}$-Weighted MRI Scans in the Entire Group and Stratified by Risk Group and Serostatus*

\begin{tabular}{|c|c|c|c|c|c|c|c|c|c|}
\hline & \multirow[b]{2}{*}{ All } & \multicolumn{4}{|c|}{ Gay Men } & \multicolumn{4}{|c|}{ PDUs } \\
\hline & & All & HIV+ & HIV- & म & All & HIV+ & HIV- & मे \\
\hline $\begin{array}{l}n \\
\text { Atrophy }\end{array}$ & 233 & 118 & 75 & 38 & 5 & 115 & 54 & 52 & 9 \\
\hline None & 6 & 1 & 1 & 0 & 0 & 5 & 3 & 2 & 0 \\
\hline Mild & 178 & 82 & 53 & 27 & 2 & 96 & 46 & 41 & 9 \\
\hline Moderate & 45 & 32 & 20 & 9 & 3 & 13 & 4 & 9 & 0 \\
\hline Marked & 1 & 0 & 0 & 0 & 0 & 1 & 1 & 0 & 0 \\
\hline मे & 3 & 3 & 1 & 2 & 0 & 0 & 0 & 0 & 0 \\
\hline \multicolumn{10}{|c|}{$\begin{array}{l}\text { Foci of increased } \\
\text { signal }\end{array}$} \\
\hline None & 185 & 97 & 64 & 29 & 4 & 88 & 41 & 41 & 6 \\
\hline Single & 23 & 14 & 7 & 6 & 1 & 9 & 3 & 5 & 1 \\
\hline Few & 11 & 6 & 3 & 3 & 0 & 5 & 4 & 0 & 1 \\
\hline Multiple & 10 & 1 & 1 & 0 & 0 & 9 & 4 & 5 & 0 \\
\hline Diffuse & 2 & 0 & 0 & 0 & 0 & 2 & 1 & 1 & 0 \\
\hline मे & 2 & 0 & 0 & 0 & 0 & 2 & 1 & 0 & 1 \\
\hline
\end{tabular}

* MRI indicates magnetic resonance imaging; HIV, human immunodeficiency virus; plus and minus signs, positive and negative, respectively; PDUs, parenteral drug users; and star, missing data.

Table 4.-Results of Routine $\mathrm{T}_{2}$-Weighted MRI Scans Stratified by Severity of HIV Infection*

\begin{tabular}{|lrrrrrrr|}
\hline & & \multicolumn{7}{c|}{ Stage } \\
\cline { 3 - 8 } & All & 0 & 1 & 2 & 3 & 4 & 4 \\
\hline$n$ & 233 & 90 & 19 & 33 & 68 & 9 & 14 \\
\hline $\begin{array}{l}\text { Atrophy } \\
\text { None }\end{array}$ & 6 & 2 & 0 & 3 & 1 & 0 & 0 \\
\hline Mild & 178 & 68 & 16 & 24 & 52 & 7 & 11 \\
\hline Moderate & 45 & 18 & 2 & 6 & 14 & 2 & 3 \\
\hline Marked & 1 & 0 & 0 & 0 & 1 & 0 & 0 \\
\hline WMHs & 3 & 2 & 1 & 0 & 0 & 0 & 0 \\
\hline None & 185 & 70 & 17 & 27 & 54 & 7 & 10 \\
\hline Single & 23 & 11 & 1 & 2 & 7 & 0 & 2 \\
\hline Few & 11 & 3 & 1 & 2 & 3 & 1 & 1 \\
\hline Many & 10 & 5 & 0 & 1 & 3 & 1 & 0 \\
\hline Diffuse & 2 & 1 & 0 & 0 & 1 & 0 & 0 \\
\hline מ & 2 & 0 & 0 & 1 & 0 & 0 & 1 \\
\hline
\end{tabular}

MRI indicates magnetic resonance imaging; HIV, human immunodeficiency virus; WMHs, white-matter signal hyperintensities; stage 0 , HIV negative; 1, HIV positive, asymptomatic; 2, HIV positive with mild symptoms (eg, enlarged lymph nodes); 3 , acquired immunodeficiency syndrome-related complex; 4, acquired immunodeficiency syndrome; and star, missing data.

overall degree of neurologic disability, CD4 count, or serostatus. The mean age of subjects with WMH (43.0 years) was significantly higher than that of subjects without WMH (38.9 years) $(t=3.18, P=.002)$. There was no relationship between atrophy and WMH.

In the HIV-positive subjects, there were no significant associations between either atrophy or WMH and CD4 or CD8 counts, GPR, clinical neuropsychologic impression, or overall neurologic disability.

For the HIV-negative subjects, WMH increased in frequency with atrophy $\left(\chi^{2}=4.7, P=.030\right)$, but there were no other associations between MRI variables and medical, neurologic, or neuropsychologic variables.

No relationships existed between the MRI findings and neurologic or neuropsychologic variables in either the gay men as a group or the PDU cohort.

There were no relationships between the MRI findings and other variables in the HIV-positive gay men, HIV-positive PDU, and HIV-negative PDU groups; however, WMH increased with atrophy in the HIV-negative gay men $\left(\chi^{2}=4.8, P=.029\right)$.

A subgroup, the initial 50 subjects, had \%CSF calculations performed. Subjects with inadequate or incomplete scans and the eight subjects with focal lesions were excluded from this subgroup (described in Table 5). As the WMH were not visualized on the heavily $\mathrm{T}_{2}$-weighted scans, they were not believed to contribute to the \% CSF calculations, and these subjects were not excluded from the analysis. Within this subgroup, there were no differences between the HIV-positive and HIV-negative subjects with respect to age, educa-
Table 5. - Subgroup of Subjects With Intracranial Water Percent (\% CSF), Contrasted With the Entire Group

\begin{tabular}{|lcc|}
\hline & $\%$ CSF & All \\
\hline$n$ & 43 & 233 \\
Age, y & $41.8(8.5)$ & $39.7(7.8)$ \\
Education, y & $15.0(3.0)$ & $14.0(3.3)$ \\
CD4, No. mm $^{3}$ & $488.1(344)$ & $578.1(385)$ \\
CD4/CO8 ratio & $0.71(0.6)$ & $0.81(0.6)$ \\
Gay men & 27 & 118 \\
PDUs & 16 & 115 \\
HIV+ & 31 & 129 \\
HIV- & 12 & 90 \\
HIV+ gay men & 23 & 75 \\
HIV- gay men & 4 & 38 \\
HIV+ PDUs & 8 & 54 \\
HIV- PDUs & 8 & 52 \\
\hline
\end{tabular}

"HIV indicates human immunodeficiency virus plus and minus signs, positive and negative, respectively; and PDUs, parenteral drug users. Numbers in parentheses are SDs.

tion, GPR, clinical neuropsychologic impression, overall neurologic disability, atrophy rating, or WMH. Moreover, they did not differ from the subjects without \%CSF calculations with respect to these factors. Intracranial water percent correlated with age $(r=.3763, P=.013)$ and the radiologist's rating of atrophy $(r=.5031$, $P=.001$ ). After controlling for age, $\% \mathrm{CSF}$ still correlated with the subjective rating of atrophy $(r=.5240$, $P=.000$ ), and there was a negative correlation with both the CD4 count $(r=-.3959, \quad P=.009)$ and the $\mathrm{CD} 4 / \mathrm{CD} 8$ ratio $(r=-.3071$, $P=.0488$ ). Intracranial water percent adjusted for age was not significantly increased in the HIV-positive subjects compared with the HIV-negative subjects, nor were there any statistically significant relationships between $\%$ CSF and neurologic or neuropsychologic summary variables.

\section{COMMENT}

The frequency of neurologic involvement in AIDS has engendered numerous attempts to detect early neurologic or neuropsychologic changes in HIVinfected individuals who have not developed AIDS. A number of studies have demonstrated differences between HIV-positive and HIV-negative subjects ${ }^{2530}$; others, a continuum of change across stages ${ }^{31,32}$; and others, no differences between seropositive and seronegative subjects..$^{33-25}$ In the follow-up study, we noted slight impairment on neuropsychologic tests associated with subtle neurologic signs and symptoms in the HIV-positive subjects that were believed to be without functional consequence. ${ }^{9}$ The suggestion that there may be subtle changes early in the course of HIV infection raises the question of whether or not there is a preceding or concomitant structural CNS change 


\begin{tabular}{|c|c|c|c|c|}
\hline \multicolumn{5}{|c|}{ Table 6.-Magnetic Resonance Imaging and HIV* } \\
\hline Source, $y$ & $\mathbf{n}$ & Atrophy & WMHs & Stage of Illness \\
\hline Levy et al,' 1986 & 6 & NA & $5 / 6$ & AIDS, no controls \\
\hline Shabas et al, ${ }^{44} 1987$ & 1 & $1 / 1$ & $1 / 1$ & AIDS, no controls \\
\hline Grant et al, ${ }^{45} 1988$ & 23 & $9 / 13^{a} ; 5 / 10^{b}$ & $10 / 23^{o \cdot b}$ & a indicates AIDS, $b$, ARC \\
\hline Post et al, ${ }^{4} 1988$ & 7 & $6 / 7$ & $5 / 7$ & AIDS, no controls \\
\hline Ekholm and Simon, ${ }^{46} 1988$ & 3 & $3 / 3$ & $3 / 3$ & ARC, no controls \\
\hline Olsen et $\mathrm{al}_{1}{ }^{3} 1988$ & 365 & $63 / 365$ & $112 / 365$ & AIDS, no controls \\
\hline Trotot et al, ${ }^{39} 1988$ & 15 & NA & $4 / 15$ & HIV+, no symptoms \\
\hline Freund-Levi et al, ${ }^{47} 1989$ & 4 & $0 / 4$ & $0 / 4$ & Seropositive only \\
\hline Subsequent scans & 3 & $3 / 3$ & $1 / 3$ & AIDS (transfusion) $\dagger$ \\
\hline \multirow[t]{3}{*}{ MacArthur et al, ${ }^{7} 1990$} & 149 & NA & $18 / 62$ & HIV - gay men controls \\
\hline & & & $33 / 128$ & HIV+ no symptoms $¥$ \\
\hline & & & $3 / 17$ & HIV+ symptomatic \\
\hline Levy et al, $^{2} 1990$ & 50 & $6 / 50$ & $2 / 50$ & AIDS, no controls \\
\hline Kieburtz et al, ${ }^{41} 1990$ & 52 & $30 / 52$ & $26 / 52$ & $\begin{array}{l}\text { HIV+ no symptoms, } 12 ; \\
\text { ARC, 14; AIDS, } 26\end{array}$ \\
\hline Kupfer ef al, ${ }^{5} 1990$ & 130 & $44 / 130$ & NA & AIDS, no controls \\
\hline Chrysikopoulos et al, ${ }^{6} 1990$ & 14 & $8 / 10$ & $5 / 10$ & AIDS, no controls \\
\hline \multirow[t]{4}{*}{ Levin et al, ${ }^{38} 1990$} & 32 & NA & $1 / 7$ & HIV - \\
\hline & & & $2 / 9$ & $\operatorname{CDC} \|$ \\
\hline & & & $2 / 11$ & CDC III \\
\hline & & & $2 / 5$ & CDC IV \\
\hline \multirow[t]{2}{*}{ Koralnik et $\mathrm{al}_{,}{ }^{48} 1990$} & 62 & $0 / 33$ & $1 / 33$ & HIV - gay men controls \\
\hline & & $1 / 29$ & $0 / 29$ & HIV+ no symptoms \\
\hline Subsequent scans & & $1 / 27$ & $1 / 27$ & HIV+ no symptoms \\
\hline \multirow[t]{2}{*}{ Post et al, ${ }^{40} 1991$} & 119 & $2 / 95$ & $11 / 95$ & HIV+ no symptoms \\
\hline & & $9 / 24$ & $8 / 24$ & HIV+ symptomatic \\
\hline \multirow[t]{2}{*}{ Present study } & 233 & $86 / 90$ & $20 / 90$ & HIV- \\
\hline & & $138 / 143$ & $28 / 143$ & HIV+ \\
\hline
\end{tabular}

*HIV indicates human immunodeficiency virus; plus and minus signs, positive and negative, respectively; WMHs, white-matter signal hyperintensities; NA, not available; AIDS, acquired immunodeficiency syndrome; ARC, AIDS-related complex; and CDC II, III, and IV, AIDS stages II, III, and IV, respectively, using the Centers for Disease Control criteria.

tFour transfusion recipients with serial scans.

‡Refers to medical or systemic symptoms, such as weight loss or fatigue, but without evidence of AIDS; ex. cludes patients with tumors or opportunistic infections.

that might be identified on MRI scans.

Aside from opportunistic infections and neoplasms, the main focuses of radiologic studies in HIV disease have been subcortical WMH on MRI and diffuse brain atrophy (Table 6). Whitematter signal hyperintensities have been noted predominantly in the subcortical and periventricular white matter areas. Because these locations are identical to those with pathologic changes in the AIDS dementia complex, ${ }^{3,36}$ many believed that they might represent early signs of direct HIV infection of the CNS. ${ }^{4.28}$ We noted no relationship between WMH and GPR, clinical neuropsychological impression, overall neurologic disability, severity of illness, or serostatus. We did find, however, that WMH increased with age and that they were seen in association with increased atrophy in the HIV-negative gay men. A similar increase in WMH with age has been noted in the general population ${ }^{37}$ and the increased age (although not statistically significant) of the HIV-negative gay men may be confounding the finding in this group. In a prospective study, McArthur et $\mathrm{al}^{7}$ noted frequencies of white-matter abnormalities among HIV-negative
(24\%), asymptomatic HIV-positive $(26 \%)$, and symptomatic HIV-positive (17\%) subjects similar to those in this study. They found no correlations between clinical findings or CD4 counts and WMH. In unselected subjects with serial scans, they found no interval changes in WMH in either HIV-negative or HIV-positive subjects and concluded that those were probably incidental findings of no clinical significance. Likewise, no differences in the frequency of WMH across stages of HIV infection from seronegative subjects to CDC stages II, III, and IV were seen by Levin et al. ${ }^{38}$ Foci of increased signal were noted in four of 15 asymptomatic HIV-positive subjects without relation to age, sex, risk group, or CD4 count by Trotot et al. ${ }^{39}$ In light of these reports, and the lack of clinical neurologic or neuropsychologic correlates to these WMH, we suspect that they are not clinically meaningful. However, Post et $\mathrm{ll}^{10}$ found WMHs in $17 \%$ of their prospectively studied HIV-positive subjects. They noted WMH to be more extensive and more frequent in neurologically symptomatic subjects, and that led them to suggest that these were HIV-related changes. Hopefully, serial scans and pathologic findings will provide a definitive conclusion.

We did not appreciate any examples of the lesion described by Kieburtz et $\mathrm{al}^{\mathrm{H}}$ (concerning an area of WMH in the corpus callosum and fornix); however, there were many differences between their study and ours: their study was retrospective, had a population selected for CNS complaints, and lacked HIVnegative control subjects. Furthermore, differences between our results and those of other investigators with regard to the presence or absence of WMH may reflect differing imaging techniques. The use of a 1.5-tesla MRI scanner provides high signal detection and resolution capabilities. On the other hand, the absence of $\mathrm{T}_{1}$-weighted or proton-density images may limit our ability to fully characterize signal abnormalities.

Atrophy seen on computed tomographic scans was predictive of clinical progression in one study of patients with AIDS, ${ }^{1}$ and it has been noted as a common finding in retrospective MRI studies.$^{36}$ In a prospective MRI study of HIV-positive subjects, Post et a ${ }^{40}$ noted an association between the presence of cortical atrophy and abnormalities on neurologic examination, CD4 counts less than $400 / \mathrm{mm}^{3}$, serum p24 antigen greater than $20 \mu \mathrm{g} / \mathrm{mL}$, and elevated p24 and IgG levels in CSF. The authors caution, however, that atrophy based on observer ratings is subject to variability, as well as differing definitions of MR abnormalities by different observers. This latter caveat may explain the fact that they found atrophy to be present in only $8 \%$ of their sample, while we found at least a minor degree of atrophy to be nearly universal. In our study, all scans were rated by the same neuroradiologist (J.B.) blind to HIV status and clinical data except for age. Atrophy, while seen more commonly in the gay men, did not correlate with any of the neurologic, neuropsychologic, or medical variables in subjects without AIDS.

Finding atrophy more commonly in the gay men seems almost counterintuitive. The gay men had significantly better neuropsychologic performance and fewer neurologic abnormalities than the did the PDU cohort. In addition, one might suspect that alcohol use and head injury, as well as parenteral drug use, would be more common in the PDU group and might conceivably contribute to atrophy on MRI scans. Yet, we found no relationship between atrophy and the neurologic or neuropsychologic findings and the alcohol issue becomes quite complex when one considers that abstinent alcoholics show reversal of brain atrophy on MRI ${ }^{42}$ Furthermore, the effect, if any, of parenteral drug use on 
cerebral atrophy is unclear.

Neither atrophy nor WMH seen on routine MRI distinguished HIV-positive from HIV-negative subjects. Only the few cases with AIDS defining lesions clearly distinguished HIV-positive from HIV-negative subjects. Realizing that the neurologic and neuropsychologic changes noted early in HIV infection are subtle, we sought a finer gauge for atrophy in addition to subjective rating by a trained observer- a computer-generated calculation of \% CSF in a manually traced region of interest produced a quantitative measure of atrophy. Others ${ }^{43}$ have shown such measurements to vary with age in normal subjects. Levin et al $^{38}$ in a study of 32 subjects noted increased \% CSF in subjects with stage IV disease (per the Centers for Disease Control criteria) compared with others and also noted slower simple reaction times, slower performance on the trails $B$ test, and poorer performance on the Benton visual retention test with increasing \%CSF. In our study, atrophy rating did not correlate significantly with age, suggesting that our subjective ratings of atrophy were valid for the subject's age. That \%CSF correlated with atrophy rating, particularly when controlled for age, further supports our notion that the subjective atrophy ratings were valid for the subject's age. The finding that age-adjusted \%CSF values correlated inversely with $\mathrm{CD} 4$ counts and $\mathrm{CD} 4 / \mathrm{CD} 8$ ratios suggests that there is loss of brain volume and replacement by CSF in association with progression of HIV infection (as measured by CD4 counts) independent of, or preceding, clinical neurologic or neuropsychologic effects. Whether this may be due to direct viral effects, toxic effects of viral proteins, activation of other infectious agents, or activation of neuronal genes or autoimmune or other phenomena remains unknown.

We conclude that routine MRI of the brain in asymptomatic and mildly symptomatic individuals with HIV infection is not different from noninfected individuals in similar risk groups. Further, we speculate that quantitative measures of atrophy that correlate with immunologic measures may demonstrate differences between HIV-positive and HIV-negative subjects. Follow-up scans to assess the interval changes in $\mathrm{CSF}$ volumes and their relationship to HIV-related neurologic disease may help to define such differences.

This study was supported by federal grant P50-1MH43520 and additionally by grant MH44959.

\section{References}

1. Levy R, Rosenbloom S, Perret L. Neuroradiologic findings in AIDS: a review of 200 cases.
AJR Am J Roentgenol. 1986;147:977-983.

2. Levy R, Mills C, Posin J, Moore S, Rosenblum $\mathrm{M}$, Bredesen $\mathrm{D}$. The efficacy and clinical impact of brain imaging in neurologically symptomatic AIDS patients: a prospective CT/MRI study. $J$ AIDS 1990;3:461-471

3. Olsen W, Longo F, Mills C, Norman D. White matter disease in AIDS: findings at MR imaging. Radiology. 1988;169:445-448.

4. Post M, Tate L, Quencer R, et al. CT, MR, and pathology in HIV encephalitis and meningitis. AJR Am J Roentgenol. 1988;15:373-380.

5. Kupfer M, Zee C, Colletti P, Boswell W, Rhodes R. MRI evaluation of AIDS-related encephalopathy: toxoplasmosis vs lymphoma. Magn Reson Imaging. 1990;8:51-57.

6. Chrysikopoulos H, Press G, Grafe M, Hesselink J, Wiley C. Encephalitis caused by human immunodeficieney virus: $\mathrm{CT}$ and $\mathrm{MR}$ imaging manifestations with clinical and pathologic correlation. Radiology. 1990;175:185-191.

7. McArthur J, Kumar A, Johnson D, et al. Incidental white matter hyperintensities on magnetic resonance imaging in HIV-1 infection. $J$ AIDS 1990;3:252-259.

8. Gorman J, Kertzner R, Todak G, et al. Multidisciplinary baseline assesment of gay men with and without HIV infection, I: overview of study design. Arch Gen Psychiatry. 1991;48:120-123.

9. Stern Y, Marder K, Bell K, et al. Multidisciplinary baseline assessment of gay men with and without HIV infection, III: neurological and neuropsychological findings. Arch Gen Psychiatry. 1991:48:131-138

10. Kurtzke J. Rating neurologic impairment in multiple sclerosis: an expanded disability status scale (EDSS). Neurology. 1983;33:1444-1452.

11. Stern Y, Sano M, Paulson J, Mayeux R. Modified mini-mental state examination: validity and reliability. Neurology. 1987;37:179.

12. Wechsler D. Wechsler Adult Intelligence Scale-Revised. New York, NY: The Psychological Corporation; 1981

13. Buschke H, Fuld P. Evaluating storage, retention, and retrieval in disordered memory and learning. Neurology. 1974;24:1019-1025.

14. Wechsler D. A standardized memory scale for clinical use. $J$ Psychol. 1945;19:87-95.

15. Kaplan E, Goodglass H, Weintraub S. Boston Naming Test. Philadelphia, Pa: Lea \& Febiger 1983.

16. Benton A. FAS test. In: Spreen O, Benton A, eds. Neurosensory Center Comprehensive Examination for Aphasia. Victoria, British Columbia: University of Victoria; 1967.

17. Goodglass H, Kaplan D. The Assessment of Aphasia and Related Disorders. 2nd ed. Philadelphia, Pa: Lea \& Febiger; 1983.

18. Flowers K, Robertson C. The effect of Parkinson's disease on the ability to maintain a mental set. J Neurol Neurosurg Psychiatry. 1985;48:517529.

19. Reitan R, Wolfson D. The Halstead-Reitan Neuropsychological Test Battery: Theory and Clinical Interpretation. Tueson, Ariz: Neuropsychology Press; 1985.

20. Sano M, Rosen W, Mayeux R. Attention Deficits in Alzheimer's Disease. Washington, DC: American Psychiatric Association; 1984

21. Willner A. Towards development of more sensitive clinical tests of abstration: the analogy test. Proc Ann Conv Am Psychol Assoc. 1970;5:553-554.

22. Benton A. The Visual Retention Test. New York, NY: The Psychological Corporation; 1955.

23. Stroop J. Studies in interference in serial verbal reactions. $J$ Exp Psychol. 1935;18:643-661.

24. Benton A, Hamsher K, Varney N, Spreen O. Contributions to Neuropsychological Assessment. New York, NY: Oxford Press; 1983.

25. Raven J. Standard Progressive Matrices. Great Britain: HK Lewis and Co Ltd; 1960.

26. Fleiss J. Statistical Methods for Rates and Proportions. New York, NY: John Wiley \& Sons Inc; 1981.

27. SAS User's Guide: Statistics. 5 ed. Cary,
NC: SAS Institute; 1988

28. Grant I, Atkinson J, Hesselink J, et al. Evidence for early central nervous system involvement in the acquired immunodeficiency syndrome and other HIV infections. Ann Intern Med. $1987 ; 107: 828-836$

29. Tross S, Price R, Navia B, et al. Neuropsychological characterization of the AIDS dementia complex: a preliminary report. AIDS. 1988;2:81-88.

30. Poutianen E, Livainen M, Valle S, et al. Cognitive changes as early signs of HIV infection. Acta Neurol Scand. 1988;78:49-52.

31. Janssen R, Saykin A, Kaplan J, et al. Neurological symptoms and neuropsychological abnormalities in lymphadenopathy syndrome. Ann Neutol. 1988; 23(suppl):S17-S18.

32. Selnes O, McArthur J, Munoz A, et al. Longitudinal neuropsychological evaluation of healthy HIV-1 infected men: MACS study. In: IV International Conference on AIDS, Stockholm 1988. Frederick, Md: University Publishing Group; 1988. Abstract.

33. Janssen R, Saykin A, Cannon L, et al. Neurological and neuropsychological manifestations of HIV-1 infection: association with AIDS-related complex but not asymptomatic HIV-1 infection. Ann Neurol. 1989;26:592-600.

34. McArthur J, Cohen B, Selnes O, et al. Low prevalence of neurological and neuropsychological abnormalities in otherwise healthy HIV-1-infected individuals: results from the Multicenter AIDS Cohort Study. Ann Neurol. 1989:26:601-611.

35. Goethe C, Mitchell J, Marshall D, et al. Neuropsychological and neurological function of HIV seropositive individuals. Arch Neurol. 1989;46:129-133.

36. Navia B, Cho E-S, Petito C, Price R. The AIDS dementia complex, II: neuropathology. Ann Neurol. 1986;19:525-535.

37. George A, de Leon M, Kalnin A, Rosner L, Goodgold A, Chase N. Leukoencephalopathy in normal and pathologic aging, II: MRI of brain lucencies. $A J N R .1986 ; 7: 567-570$.

38. Levin H, Williams D, Borucki M, et al. Magnetic resonance imaging and neuropsychological findings in human immunodeficiency virus infection. J AIDS. 1990;3:757-762.

39. Trotot $\mathbf{P}$, Cabanis $\mathrm{E}$, Lavayssiere $\mathrm{R}$, et al. Apport de l'IRM cerebrale a l'etude des facteurs pronostiques du SIDA. J Radiol. 1988;69:193-196.

40. Post M, Berger J, Quencer R. Asymptomatic and neurologically symptomatic HIV-seropositive individuals: prospective evaluation with cranial MR imaging. Radiology. 1991;178:131-139.

41. Kieburtz K, Ketonen L, Zettelmaier A, Kido D, Caine E. Simon J. Magnetic resonance imaging findings in HIV cognitive impairment. Arch Neurol. 1990;47:643-5.

42. Schroth G, Naegele T, Klose U, Petersen D. Reversible brain shrinkage in abstinent alcoholics, measured by MRI. Neuroradiology. 1988;30:385389.

43. Condon B, Grant R, Hadley D, Lawrence A. Brain and intracranial cavity volumes: in vivo determination by MRI. Acta Neurol Scand. 1988;78:387-393.

44. Shabas D, Gerard G, Cunha B, Rossi D. MRI appearance of AIDS subacute encephalopathy. Comput Radiol. 1987;11:69-73.

45. Grant I, Atkinson J, Hesselink J, et al. Human immunodeficiency virus-associated neurobehavioral disorder. $J R$ Coll Physicians Lond. 1988;22:149-157.

46. Ekholm S, Simon J. Magnetic resonance imaging and the acquired immunodeficiency syndrome dementia complex. Acta Radiol. 1988;29:227-230.

47. Freund-Levi Y, Saaf J, Wahlund L-O, Wetterberg $\mathrm{L}$. Ultra low field brain MRI in HIV transfusion infected patients. Magn Reson Imaging. 1989:7:225-230

48. Koralnik I, Beaumanoir A, Hausler R, et al. A controlled study of early neurologic abnormalities in men with asymptomatic human immunodeficiency virus infection. $N$ Engl J Med. 1990;323:864870 